\title{
Domingo no Neo-Realismo Português
}

Sunday in The Portuguese Neo-Realism

Isadora Dutra

UNIANDRADE, Curitiba, PR, Brasil

Resumo: $\mathrm{O}$ artigo descreve as transformações do narrador no Neo-realismo português a partir do romance Domingo à Tarde, de Fernando Namora. O texto também aborda o problema da classificação do Neo-realismo com as mudanças no discurso romanesco na década de 50 . O estudo da obra de Namora revela um narrador participante e existencialista, diferente da voz objetiva e monológica dos primeiros romances neo-realistas.

Palavras-chave: Literatura Portuguesa; Neo-realismo; Fernando Namora; narrador; existencialismo.

Abstract: The article describes the transformations of the narrator in the portuguese Neo-realism from Fernando Namora's novel Domingo à tarde. The text also approach the classification problem of Neo-realism with the novel's discourse changes in the 50's. The study of Namora's work reveals a participant and existentialist narrator, a different one from the objective and monological voice of the first neo-realists novels.

Keyword: Portuguese Literature; Neo-realism; Fernando Namora; narrator; existentialist.

Uma característica do momento neo-realista na literatura portuguesa é a grande controvérsia teórica que o movimento gerou na crítica literária. Para além dos aspectos estéticos e ideológicos, apesar desses representarem justamente o motivo das divergências, uma das questões relevantes desse período está associada à dificuldade de classificação das obras e principalmente de compreensão do neo-realismo como unidade literária que se mantém na continuidade histórica ou como movimento de época específica e já acabado.

A primeira interpretação leva em consideração a ideia de trajeto evolutivo dividido em fases (alguns autores apontam duas fases, outros três) definidas por certos tipos de obras e marcado por transformações formais que acompanham as alterações ideológicas, entendendo o neo-realismo como um projeto em que a expressão estética está acoplada à difusão ideológica. Partilhando dessa concepção, estética somada à ideologia, a segunda manei- 
ra de entender o movimento assume, no entanto, outro caminho bem diferente em direção à ideia de que as mudanças acabam por desconfigurar o que era a origem do neo-realismo e as obras que não correspondem às primeiras marcas típicas do mesmo já não são neo-realistas, tendo findado o projeto.

Qualquer das duas versões parte do mesmo problema: como avaliar as obras produzidas no período, se pela perspectiva da alteração dos procedimentos narrativos ou se pela abordagem da evolução ideológica. Nenhuma das partes nega, porém, a estreita ligação que o Neo-realismo estabeleceu entre as escolhas técnicas em relação ao texto e aquelas de caráter ideológico ligadas ao materialismo e a dialética marxistas, além de recorrer a outras áreas como história, filosofia e psicologia, que servem de sustentáculo para a criação artística. É frequentemente 154 apontada entre os autores que tratam do assunto a intenção dos neo-realistas de promover uma literatura voltada para o desenvolvimento da consciência social de classes.

\footnotetext{
Propunha, consequentemente, a literatura portuguesa dos anos 40 que a arte não era apenas um prazer estético, mas servia a um proveito essencial do homem, contribuindo para o desenvolvimento da consciência e melhoria da ordem social. Essa proposição vem demonstrar que o artista e, principalmente, o literato está comprometido com a sociedade, subordinando seu "eu individual" ao "eu social". Toda obra artística portuguesa, a partir dos anos 40, exprime, então, determinada posição político-social como a produção artística surgida ao desenrolar da década de 30 no mundo ocidental. (REMÉDIOS, 1986, p. 14)
}

Tal proposta, baseada no entendimento da época do texto literário como veículo de difusão de ideologia, estando, portanto, a serviço de uma militância e não mais tendo significado unicamente estético, acaba provocando a utilização de determinados recursos formais narrativos que privilegiam o conteúdo das obras. Nesse sentido, Carlos Reis aponta duas opções para o Neo-realismo que convergem, no entanto, para uma única concepção predominantemente conteudista:

(...) por um lado, a de se fazer do discurso literário um espaço de manifestação explícita da ideologia, enquanto componente importante da vida que se pretendia documentar, por meio de um 
processo de relacionamento que os teóricos mais esclarecidos encaminharam para o campo da verossimilhança; por outro lado, a que, reconhecendo e respeitando a dimensão estética da literatura, leva a desvanecer a missão meramente utilitária que a referida manifestação explícita pressupõe, e a subordinar a representação da ideologia (agora mediatamente documental) à ambiguidade própria da linguagem literária. Em qualquer caso, porém, acaba sempre por se afirmar, aberta ou veladamente, uma concepção conteudista do fenômeno literário. (REIS, 1983, p. 176)

Domingo no Neo-Realismo

A função da literatura é concebida no Neo-Realismo no sentido de divulgação de ideias e, a partir delas, de propiciar o desenvolvimento da consciência em termos sociais. O efeito dos pressuPortuguês postos ideológicos no texto literário é a valorização da tendência realista de representação e seus consequentes processos narrativos. Ou seja, a uma postura ideológica definida e à maneira de entender o funcionamento da literatura corresponde determinado tipo de narrativa e técnicas para realizá-la.

Se o objetivo primordial da narrativa neo-realista é de conscientizar os leitores em relação aos processos sociais e políticos em Portugal, criticando e denunciando as situações de desigualdade e injustiça, o discurso literário volta-se para a representação mais objetiva da realidade. Para tanto, as obras do período recorrem a algumas características fundamentais como a escolha do romance, por exemplo, como meio de expressão. Além disso, a literatura da década de 40, considerada por Maria Luiza Remédios (1986) como a primeira fase do Neo-Realismo, representada por romances como Gaibéus, de Alves Redol, e Esteiros, de Pereira Gomes, é marcada pela temática regional e presença das classes de trabalhadores explorados e marginalizados pelo poder do capital.

Outros pontos em comum entre as obras da primeira fase são a narração objetiva e a ação que transcorre no passado. Os dois procedimentos textuais conferem certa distância do narrador em relação às ações e heróis, sempre coletivos ao invés de individualizados como acontece no segundo momento. É justamente o tipo de narrador que concentra as grandes diferenças entre as narrativas de uma fase para outra do Neo-realismo. A década de 50, seguindo a divisão proposta por Maria Luiza Remédios (1986), corresponde à segunda fase do movimen- 
to com romances como Domingo à tarde, de Fernando Namora, e Aparição, de Vergílio Ferreira, com narradores que vão aos poucos sendo transformados, principalmente perdendo a onisciência.

A mudança do narrador provoca na narrativa neo-realista a passagem da objetividade inicial do movimento para a subjetividade que passa a configurar os romances seguintes. É pelo discurso do narrador que o leitor tem acesso às ações narradas e conhece os personagens que dela fazem parte. 0 caráter monológico ou dialógico do texto está diretamente relacionado a uma concepção de mundo que se pretende manifestar. A intenção de difundir determinada ideologia é realizada, portanto, através do tipo de discurso promovido pelo narrador: "através da sua palavra é possível a apresentação do universo romanesco" (REMÉDIOS, 1986, p. 14-15). Dessa forma, compreende-se, por exemplo, como acontece a crítica da realidade social portuguesa dos anos 40 a partir do distanciamento do narrador onisciente que confere ao texto a marca da objetividade necessária para denunciar e conscientizar.

No contexto mundial da Segunda Guerra e das mudanças em Portugal, em processo de rápida industrialização, o narrador neo-realista funciona como elemento dominante na narrativa, reproduzindo as relações de poder da sociedade. Toda a narrativa é revelada pela visão do narrador que comanda tanto a sequência e a escolha dos fatos a serem contados, quanto o que deve ser mostrado sobre os personagens, invadindo a consciência de cada um deles. Assim, o leitor conhece a narrativa através de uma voz única e o caráter monológico do texto dá o sentido do autoritarismo que rege a vida portuguesa da época.

\footnotetext{
Tanto em Gaibéus como em Esteiros, verifica-se que o narrador é o elemento que revela, de seu campo de visão, o sentido total e decisivo da denúncia contra a sociedade autocrata. Sujeito no universo ficcional, apresenta ao leitor o processo político que se desenvolve simultaneamente à intriga. Desse modo, o narrador reduplica o autoritarismo vigente na sociedade ribatejana, porque ele se instala e dirige as narrativas como o poder capitalista o faz na sociedade (REMÉDIOS, 1986, p. 125)
}

Na chamada primeira fase, a narrativa é revelada monologicamente sem que a perspectiva do narrador se confunda ou aproxime da dos heróis (que correspondem a grupos sociais). A visão 
do narrador engloba todas as demais visões mantendo a distância em relação aquilo que narra através do afastamento temporal, narrando o passado. A condição do narrador é de autoridade e não de correspondência com os personagens.

$\mathrm{Na}$ década de 50, ocorre uma mudança no discurso romanesco. É nesse ponto que, para alguns, o Neo-Realismo avança para nova fase (dos anos 50 até início da década de 60) e, para outros, inicia o processo de esgotamento alterando o projeto inicial. De todo modo, a mudança do narrador é a questão central nas transformações. A narrativa deixa de lado o princípio da objetividade, abrindo margem para subjetividades, expressando sobretudo a sensação de solidão e a vontade de liberdade que passam a ser tópicos essenciais das ideias da época.

Acirrada a guerra fria, o mundo divide-se entre quem detém o Domingo no Neo-Realismo Português poder e quem a ele se submete. No entanto, não se trata de considerar o mundo simplesmente por meio de dicotomias estagnadas e maniqueístas. Todos os sistemas políticos mostram-se capazes de tolher as liberdades. É um momento de tensão e desilusão diante das perspectivas ideológicas frustradas em que as preocupações dos escritores vão ganhando conotações existencialistas.

$\mathrm{Na}$ literatura portuguesa, a desilusão e até certa desesperança marcam as narrativas das décadas de 50 e 60 . Em relação ao narrador, a distância entre ele, a ação e os personagens diminui consideravelmente já que ele próprio passa a fazer parte da ação. 0 narrador muitas vezes corresponde ao herói, ou seja, está integrado àquilo que narra e, portanto, reflete em seu discurso certa confusão por contar fatos dos quais não está distanciado. $O$ leitor passa a ter contato com a narrativa a partir do ponto de vista de alguém que é participante dos acontecimentos e interage com as demais personagens. Conhecer o narrador oferece um caminho para compreender as ideologias que a narrativa inevitavelmente arrasta consigo.

Com a alteração do narrador a narrativa não mais retrata grupos sociais como personagens coletivos, mas sujeitos individualizados que tentam interpretar o que acontece a sua volta. A busca por uma consciência em relação à realidade não se interrompe, porém, a forma de buscá-la é outra. Também a voz distante e onisciente cede lugar ao narrador que, inserido na ação, não conhece tudo do que narra. É o que acontece em Domingo à tarde, de Fernando Namora, romance de 1961 apontado como representativo da segunda fase neo-realista. O que 
acontece com o médico Jorge é o inverso da mediação distanciada dos narradores anteriores. Ele não está separado da ação e o único distanciamento possível é o da memória.

A narrativa em primeira pessoa em que Jorge rememora momentos significativos de sua vida, durante o "tempo da morte" de uma de suas pacientes, Clarisse, gera a complexidade temporal do texto pela alternância do passado com o presente. A narrativa é construída, portanto, por uma dinâmica temporal que denota a primeira característica importante do personagem que narra, a necessidade de entender os fatos e a si mesmo através da interpretação daquilo que a memória propõe como realidade.

Se, para compreender os aspectos ideológicos da narrativa, é preciso analisar o narrador, nesse caso, para conhecer o narrador de Domingo à tarde, dois caminhos são possíveis: a avaliação do problema do tempo e da relação de Jorge com os outros personagens do romance. A temporalidade não linear da narrativa informa que a memória é o recurso encontrado pelo narrador para o entendimento da vida. De outro lado, o encontro com o outro significa para ele a descoberta do auto-conhecimento, num processo lento de abertura em direção aos demais.

o ponto transformador na vida do personagem é o fato que motiva a narrativa: o encontro com Clarisse, paciente com câncer em fase terminal. Através dessa relação, o narrador entra em contato consigo mesmo, conhecendo-se pela mudança de seus valores e pela descoberta de aspectos de sua personalidade até então escondidos. Logo no início do romance, tal descoberta de si através da descoberta do outro aparece na constante afirmação do personagem de que vai contar a história de Clarisse enquanto faz sucessivas revelações a seu respeito. Ele revela ao leitor, ao longo de sua narração, a própria história através da história da paciente.

Antes de prosseguir, quero dizer-vos que rol de doentes frequentava a minha consulta. Creio mesmo que deveria ter começado por aí, já que as circunstâncias me forçam ao papel de cronista dos acontecimentos que vão seguir-se. Quem deveria ter escrito esta narrativa era Clarisse, porquanto é dela, e só dela, que iremos falar (o que direi de mim é, afinal, pretencioso e abusivo) - e então estou certo de que o leitor sentiria logo um soco no peito, prenunciador de emocionantes expectativas, 
se ela o agredisse com um início assim: "Chamo-me Clarisse e vou morrer. Mas, entretanto, conheci um tipo que era médico e resolvera os seus problemas de consciência escolhendo uma especialidade cujos clientes não tinham um migalho de esperança à sua frente". Etc. Um começo bonito, embora suspeite que Clarisse nunca o teria preferido. (NAMORA, 1961, p.21)

O narrador Jorge inicia o romance falando de traços de sua perDomingo no sonalidade, por exemplo, sua arrogância, e também de seu trabalho, mas logo afirma ser a narrativa sobre clarisse. Ao imaginar o comeNeo-Realismo ço que ela poderia escrever para a própria narrativa, Jorge reconhece Português que sua imaginação provavelmente não corresponde à escolha que ela própria faria. Desse modo, Jorge revela mais dele do que dela. 0 início imaginado para Clarisse é o seu início para a história dela. Ele deixa transparecer, portanto, através de sua narração, a própria personalidade, pretendendo abordar a de Clarisse. A narrativa é estabelecida a partir do imbricamento das duas histórias, não sendo possível isolar no discurso de Jorge o que se trata realmente da paciente e o que revela dele porque uma coisa acontece a partir da outra.

Apesar de sua advertência inicial sobre narrar a história de Clarisse, é somente na terceira parte do romance que o narrador começa a falar diretamente dela ao mesmo tempo em que comenta situações no hospital. Aos poucos, é revelado o sentimento de angústia que é frequente em Jorge, além do isolamento e sensação de esvaziamento do sentido da vida: “(...) procurava o que não sabia encontrar ou procurava nem sabia o quê (...)” (p.54-55).

O personagem narrador deixa aparecer sua condição emocional falando da situação dos outros. É o que acontece em outra cena representativa da tendência de Jorge de falar de si através do outro por uma transposição da própria vida na escolha do que vai narrar, dando mais importância para aquilo com que se identifica.

\footnotetext{
No entanto, aquela frase "estou triste", depois dos ares estouvados da rapariga, revolteava o que quer que fosse dentro de mim. Viera legitimar, sabe-se lá como, a atmosfera emocional que me trouxera ali. Tanto as minhas reações como as de Lúcia e de Clarisse. (NAMORA,1961, p.60-61)
} 
Portanto, a história que tanto o narrador enfatiza ser de Clarisse também é a sua. A cena acima descrita confirma o embaralhar dos estados emocionais do narrador com os de outras personagens e revela outra característica sua: a tristeza. É possível desenhar o perfil de Jorge a partir do que diz dos outros e compreender as escolhas envolvidas na narrativa. $O$ personagem revela insatisfação em relação ao seu tipo de vida, apesar de não ter consciência disso até que Clarisse o faça alcançar essa compreensão a respeito de si. Por isso, o ponto escolhido para ser narrado é o encontro com Clarisse: por ser o ponto de transformação. Como é marca das narrativas de cunho existencialista, o personagem escolhe um acontecimento específico de sua vida, o qual alcança o significado de uma mudança profunda no curso dos acontecimentos, redefinindo suas emoções e atitudes diante da vida.

Do vazio inicial e completo distanciamento em relação aos outros, Jorge adquire uma nova percepção que é promovida por Clarisse. Sua condição anterior é de impotência diante dos demais. Em relação aos seus pacientes terminais, Jorge experimenta a sensação de cumplicidade com a doença: nem é capaz de esconder completamente a verdade para os pacientes sobre o estágio avançado do câncer, nem tem coragem de revelar-lhes toda a verdade.

Na relação com Clarisse tal impotência é descoberta e agravada, primeiro porque Clarisse percebe que ele esconde a verdade, segundo porque ele nada pode contra essa verdade. Ou seja, mentindo ou dizendo a verdade, o que lhe resta é sempre a impotência diante dos fatos. A reação do médico consiste em recorrer a "frases tranquilizadoras mas farsantes" (p.80) e adotar uma postura de distanciamento frio e arrogante: "a insociabilidade seria, pois, uma estratégia"(p.20).

A recusa em relação às verdades é uma constante no comportamento do narrador enquanto sua relação com a paciente Clarisse se estabelece com base na necessidade desesperada dela de arrancar dele alguma verdade sobre a doença ou sobre ele. A todo momento Jorge nega-se a revelar qualquer coisa. Sua atitude é a do cinismo: "Ela não me deixa como alternativa senão este cinismo de folhetim." Outra solução para Jorge é a fuga: "Eu abandonara-a no momento mais duro, fugira, ao vê-la de tripas esventradas. Fugia sempre. Mas tudo isso era a vida. A vida era tal como era, a grande porca: bolinhos e esperanças dilaceradas" (p.86).

Desiludido, o narrador evita as verdades da vida a todo custo, inclusive as suas, escondendo-se e nunca demonstrando emoção. Nesse sentido, sua condição de médico é usada para criar uma barreira entre 
o entendimento científico das coisas e a reação emocional. Sua ênfase está sempre na doença e não na pessoa. Sua apreensão dos eventos em volta nunca ultrapassam o ponto de vista médico, sem alcançar o pessoal. Mesmo os sentimentos são descritos com termos médicos e não se tornam, dessa forma, personalizados, são fenômenos biológicos identificados por uma terminologia científica e que nada tem a ver com as emoções humanas empíricas.

Com o mesmo distanciamento que aplica em tudo e todos, Jorge ainda resiste a outra evidência da vida: a morte. $O$ fator de não perenidade da condição humana se não é negado, também não é plenamente assumido e aparece como motivo de perturbação na narrativa. É o que acontece no trecho em que alguns dos médicos do hospital conversam sobre o tema, numa cena descrita de forma alvoroçante em que os per-

Domingo no Neo-Realismo Português sonagens agitam-se imediatamente no momento em que o assunto é abordado:

\footnotetext{
Voltei-me bruscamente para o Romualdo:

- E a morte? Também se lhe pode reconhecer a nossa marca?

A Maria Armanda tinha ido a correr buscar um pires onde eu esmagasse a beata. Empurrou-me atabalhoadamente, aflita, não fosse perder a réplica. Romualdo teve um sorriso breve e laborioso. Parecia recuperar energias abaladas, como os pugilistas ao sentarem-se junto às cordas, no intervalo entre dois assaltos. (NAMORA, 1961, p. 89).
}

A morte surge numa analogia com luta, na qual os pugilistas-médicos vão perdendo suas forças. Os personagens debatem-se em torno de uma dificuldade de compreensão de algo inevitável e corriqueiro no seu cotidiano. Da mesma forma que Clarisse e Jorge debatem-se em torno da verdade. Na sequência da cena citada, o médico Romualdo conta sobre a morte do pai quando questionado por Jorge a respeito do tema. A resposta-confissão deixa explícito outra vez na narrativa o sentimento de impotência diante da morte. Algo que se intensifica por, no caso da doença de alguém próximo afetivamente, ser mais difícil, por vezes, o reconhecimento da doença.

O mesmo acontece com Jorge em relação a Clarisse. Ele demora a perceber os sinais da doença agravando-se. Ao final, as manchas no corpo da "doente" tornam-se uma evidência tardia para Jorge, pouco antes da morte dela. O personagem narrador depara-se com o sentimento já 
conhecido de impossibilidade de modificar a realidade. A impotência gera uma dicotomia na percepção de Jorge em relação ao seu trabalho. A profissão de médico está associada ao jogo de carrasco e vítima. $O$ fato de não haver salvação faz com que ele se sinta um tipo de assassino. Daí o sentimento de culpa em relação à medicina, tornando o exercício da profissão recriminável e inútil: "Na manhã seguinte, a cama de Clarisse, na enfermaria, tinha mudado de dono. Ela cumprira o que me havia anunciado. Toda a enfermaria, de súbito, me pareceu deserta e a minha missão, ali, sem objetivo." (NAMORA, 1961, p. 105).

Por isso a própria vida não faz sentido. Daí o vazio e a arrogância que o personagem anuncia no início da narrativa, evitando o "denso rescaldo das emoções" (p. 17) ou a "ratoeira das emoções" (p. 138) ou ainda o "abuso das emoções" (p. 168). Ele não quer estar "parvamente emocionado" (p. 178). A emoção para Jorge está ligada às figuras femininas do texto, pois são as mulheres (Lúcia e Clarisse) que provocam nele reações emotivas. A mulher aparece na narrativa associada à patologia em função da situação de Clarisse, sendo a doença a maneira pela qual Jorge reconhece, ou melhor diagnostica, os outros:

\footnotetext{
Assim era: eu não sabia compreender uma mulher. Em Clarisse, por exemplo, teimava em ver apenas a doente - as suas reações deviam ter sido descritas, classificadas, algures, num tratado de medicina. Tal como um enfermo, achacado de pelagra, que corre doido pelos campos. Se corre doido pelos campos, tem pelagra. É a pelagra que corre. Se aqueles raios de loucura passavam por Clarisse, se o mórbido desvario a conduzia a atitudes extremas, é porque as patologias as previam, as regulamentavam. $\mathrm{E}$ se assim não fosse? (NAMORA, Fernando, 1961, p. 180)
}

O narrador entra em estado de perdição diante das imprevisíveis reações emocionais de Clarisse e das suas também. Recolhe-se, taciturno, e relaciona-se com os outros identificando doenças e não reconhecendo pessoas. Estando a mulher relacionada simultaneamente a emoção e patologia, entende-se a própria emoção como patológica. Mas o encontro com Clarisse inverte a percepção de Jorge, que passa a considerar a ausência de emoção como doentia. Ele descobre a doença em si mesmo e, por meio da imposição da morte, percebe melhor a vida. 
Pela primeira vez, por assim dizer, nesta revolta das vísceras, eu fazia a violenta descoberta da morte - através de uma pessoa ainda viva. Durante as minhas vigílias de cigarros traspassava-me o eco de longínquas vozes.

Desejei muitas vezes ter alguém (e só então reparava, com azeda amargura, quanto tinha sido até aí desastrado nas relações humanas, quanto conduzira as pessoas a respeitarem-me por entre gélida terra-de-ninguém, a temerem-me e nunca a terem estima por mim), um amigo que interpretasse as incongruências do meu procedimento, humanizando-as a meus olhos, ajustando-as, se fosse possível, à espécie de pessoa que eu julgava ser. Eu, por mim, de modo algum as poderia ajustar. (NAMORA, 1961, p. 185-86).

Domingo no Neo-Realismo Português

O personagem de Namora reconhece afinal suas dificuldades e sai transformado de sua relação com Clarisse. Surge nele a vontade de autoconhecimento e o reconhecimento da impossibilidade de sozinho alcançá-lo. Trata-se de uma nova inversão das concepções de Jorge sobre a vida. Antes via as pessoas como "ilhas isoladas" e, depois de Clarisse, passa a desejar a presença do outro que o humanize. Jorge admite, portanto, que não é auto-suficiente. A vontade que manifesta de ter alguém que o interprete reforça a ideia de que a narrativa é também (talvez principalmente) a história de Jorge.

O médico de Domingo à tarde personifica a sensação de desilusão, de consequente vazio de sentido em relação à vida, e a vontade subitamente irreprimível de libertar-se, a qual irrompe no contexto social e ideológico da época do existencialismo. 0 personagem vive em constante estado de angústia, solidão e incredulidade face à profissão e à vida. Tomado de culpa insolúvel, Jorge também é um oprimido no seu meio, vivendo eternamente aquela "neura de domingo":

Um dia e outro dia. Semanas longas e pesadas como neura numa tarde de domingo. A chuvinha, silenciosa e furtiva, não tinha parança. Era, nas ruas, um espelho trêmulo e, cá dentro, um charco de fastio onde os ossos se atolavam. (NAMORA, 1961, p. 109)

O encontro com Clarisse também é o evento que abre seus olhos para o meio social do qual faz parte e, em relação ao qual, esforçava-se para manter-se alienado. De repente, passa a perceber a área externa ao hospital em que toda uma parte da população de Lisboa vive isolada socialmente. 
No reconhecimento do meio social, marcado por oposições de rígida hierarquia de classes e autoritarismo, como também acontece no hospital (os pacientes pobres são "submissos e aterrados"), o romance de Namora dá continuidade à intenção neo-realista de realizar a crítica da sociedade. Jorge representa uma classe social elevada alheia ao contexto. O romance de 50-60 mantém esse elemento importante do projeto inicial do Neo-realismo, porém, transforma outros, acrescentando novas perspectivas narrativas, sobretudo tornando as questões do tempo e do narrador mais complexas.

Alguns teóricos preferem considerar que a manutenção do caráter de denúncia social confirma a ideia de continuidade evolutiva do movimento. Outros deixam o enfoque teórico recair sobre as alterações 164 em relação à década de 40, tanto em termos ideológicos quanto de estrutura narrativa, o que sugere a interrupção do projeto inicial e começo de novo período estético da literatura portuguesa. No entanto, a solução de tal dilema não é o objetivo aqui, mas sim verificar quais transformações são realizadas e como.

Nesse sentido, percebe-se a crítica da sociedade dividida em classes com mudanças evidentes em relação aos primeiros romances do movimento. Um novo componente fundamental é desenvolvido na narrativa de Domingo à tarde: a individualização da busca de consciência associada à subjetividade de caráter existencialista. Fernando Namora traz a "neura de domingo" do existencialismo para o neo-realismo.

\section{REFERÊNCIAS BIBLIOGRÁFICAS}

GUIMARÃES, Fernando. A poesia da Presença e o aparecimento do Neo-realismo. $2^{\text {a }}$ ed. Porto: Brasília Editora, 1981.

MENDONÇA, Fernando. A literatura portuguesa no século XX. São Paulo: Hucitec, 1973.

NAMORA, Fernando. Domingo à tarde. $4^{\mathrm{a}}$ ed. Rio de Janeiro: Editorial Nórdica, [sd].

NAMORADO, Joaquim. Obras. Ensaios e críticas I. Uma poética da cultura. Lisboa: Editorial Caminho, 1994. 
REIS, Carlos. 0 discurso ideológico do Neo-realismo português. Coimbra: Livraria Almedina, 1983.

REMÉDIOS, Maria Luiza Ritzel. O romance português contemporâneo. Santa Maria/RS: Edições UFSM, 1986.

SEIXO, Maria Alzira. A palavra do romance. Ensaios de genealogia à análise. Lisboa: Livros Horizonte, 1986.

Domingo no

Recebido em 05 de junho de 2016 Neo-Realismo

Aceito em 02 de outubro de 2016 Português 
